\title{
Quality of life in the institutionalized elderly with dizziness complaint: a cross-sectional study
}

\author{
Adriele Lins Silva ${ }^{(1)}$ \\ Lidiane Maria de Brito Macedo Ferreira(1) \\ Raysa Vanessa de Medeiros Freitas ${ }^{(1)}$ \\ Kenio Costa de Lima ${ }^{(1)}$ \\ Ricardo Oliveira Guerra ${ }^{(1)}$
}

Karyna Myrelly Oliveira Bezerra de Figueiredo Ribeiro ${ }^{(1)}$

(1) Universidade Federal do Rio Grande do Norte, Natal, Rio Grande do Norte, Brasil.

Conflict of interests: Nonexistent

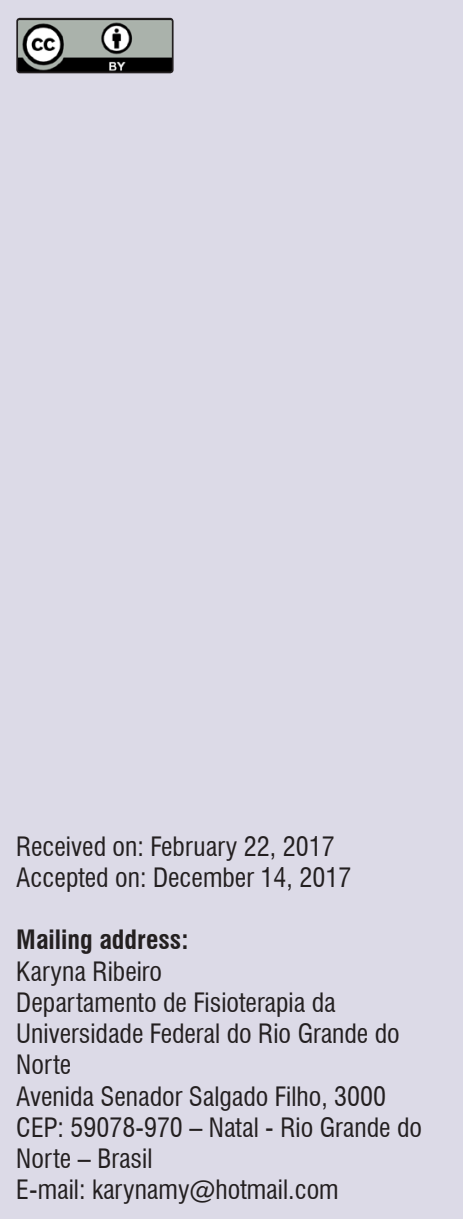

\section{ABSTRACT}

Purpose: to evaluate the quality of life in institutionalized elderly people with dizziness complaint and to relate the results to the characteristics of dizziness and functional capacity.

Methods: in this cross-sectional study, one-hundred and nineteen elderly residents in three geriatric long-term care institutions in Natal city, Brazil, were evaluated. Those who had presented dizziness in the former year (30/25.2\%) were included in this study. The quality of life was measured by the Dizziness Handicap Inventory. Functional capacity was measured by the Berg Balance Scale, the Functional Reach Test, the Unipedal Stance Test with eyes open and closed, and the Falls Efficacy Scale - International.

Results: associations were found between physical, functional and emotional aspects and the duration of dizziness $(p=0.002, p=0.041$ and $p=0.004$, respectively); the functional aspects with age $(p=0.031)$, the physical aspects with the presence of falls in the previous year $(p=0.039)$; and the physical, functional and emotional aspects of the Dizziness Handicap Inventory with fear of falling $(p=0.004, p<0.001$ and $p=0.016$, respectively).

Conclusion: institutionalized elderly with dizziness complaints had a low perception of quality of life, and the duration of dizziness, age, falls and fear of falling negatively influenced their quality of life.

Keywords: Homes for the Aged; Quality of Life; Dizziness 


\section{INTRODUCTION}

Life expectancy has been growing steadily in Brazil, leading to an increase in health services directed to the elderly population ${ }^{1}$. The aging process itself leads to biological and pathotological changes that are inherent to all living beings, and which is worsened by the associated diseases and reduction in mobility ${ }^{2}$. Consequently, institutionalization has been been considered as an important alternative to promote appropriate health care to elderly who present low functional capacity, advanced chronic diseases and dependence ${ }^{3,4}$.

Intitutionalized elderly are more likely to complain of episodes of dizziness, as they present innumerous associated health problems and a higher percentage of drug intake ${ }^{5}$. It is estimated that the prevalence of dizziness among institutionalized elderly ranges from $44 \%$ to $58 \% \%^{6,7}$. This symptom is characterized by a floating sensation, vertigo, spatial disorientation and body imbalance caused by sensory conflict between visual, vestibular and proprioceptive systems ${ }^{8}$, which represents the major cause of falls among the institutionalized elderly ${ }^{9}$.

Functional capacity refers to the potential that the elderlypresent to independently decide and act in their lives, and is also worsened by a sedentary lifestyle associated to the aging process ${ }^{10}$. This condition may increase the risk of falling and the number of hospitalizations among residents in Homes for the Aged (HA). There is a decrease in reaction time to maintain postural balance and a consequent decline in the capacity to perform activities of daily living (ADL), alterations in gait, postural instability and falls ${ }^{11}$.

Studies that evaluate the quality of life and the functional capacity in institutionalized elderly with dizziness complaints are not common in HA. Therefore, the aim of this study was to evaluate the quality of life of institutionalized elderly and to relate these results to dizziness characteristics and functional capacity of the elderly.

\section{METHODS}

\section{Study Design}

This is an analytical cross-sectional study of elderly residents of three HA conducted between September and November, 2013. The study design was based on the protocol recommendations of the Strengthening Reporting of Observational Studies in Epidemiology $(\mathrm{STROBE})^{12}$.
The research project was approved by the Research Ethics Committee of the Center for Health Sciences at the Federal University of Rio Grande do Norte, Brazil (protocol no. 309/2012). All elegible participants gave informed and signed consent.

\section{Subjects}

Elderly patients 60 years or older residing in three non-profit HA in the city of $\mathrm{Natal} / \mathrm{RN}$, Brazil, were evaluated. Elderly who presented preserved cognitive capacity measured by the Pfeiffer test and who were able to walk with or without assistance for $4 \mathrm{~m}$ were included, and those who presented musculoskeletal or neurological problems, which made performing the physical tests impossible, were excluded. One-hundred and nineteen elderly met these criteria, and those who had presented dizziness in the last year (30/25.2\%) were then included in this study.

\section{Procedures}

The elderly persons were evaluated in two phases: a semi-structured interview and collection of physical performance data. All tests were performed by the same evaluator to reduce the bias risk.

The influence of dizziness on the individual's quality of life (dependent variable) was determined by the Brazilian version of the Dizziness Handicap Inventory $(\mathrm{DHI})^{13}$, which aims to assess self-perception of the incapacitating effects of dizziness. The DHI has a score ranging from 0 to 100 and is composed of 25 questions evaluating physical, functional and emotional domains. Higher scores show greater functional damage ${ }^{14}$.

Dizziness was reported by the elderly individuals by answering the question: "Did you experience diziness in the previous year?" In order to characterize dizziness, the type and duration of dizziness, the presence or absence of neurovegetative symptoms and associated tinnitus were investigated. For characterizing the type of dizziness, the question: "What type of dizziness did you experience? Vertigo, imbalance, a floating sensation, or presyncope?" were used according to the description by Drachman and Hart (1972) ${ }^{15}$. Other analyzed variables such as falls in the previous year, use of a walking aid, age and sex were also reported.

Evaluation of functional capacity was performed using three instruments: the Brazilian version of the Berg Balance Scale (BBS), which is used to evaluate postural balance ${ }^{16}$ and has been validated for patients with vestibular dysfunction ${ }^{17}$; the Unipedal Stance Test 
(UST), which is a simple static balance test performed with both open and closed eyes, and is related to risk of falls ${ }^{18,19}$; and the Functional Reach Test (FRT), which was also used to determine the risk of falls ${ }^{20}$. Self-efficacy for falls was assessed by the Brazilian version of the Falls Efficacy Scale - International $\left(\right.$ FES-I) ${ }^{11}$.

The BBS is a reliable instrument for evaluating functional balance in elderly people ${ }^{21}$. It is composed of 14 functional tasks, such as sitting to standing, turning to look behind, and transference, with minimum and maximum scores of 0 to 56 , respectively. A score of 45 (indicating falls) was used as the cut-off point, with $91 \%$ sensitivity and $82 \%$ specificity ${ }^{21}$.

The UST is a simple standing balance test performed with both open and closed eyes related to risk of falls ${ }^{18,19}$. The cut-off points adopted for the UST with eyes open and the UST with eyes closed were $16.6 \mathrm{~s}$ and $2.2 \mathrm{~s}$ for individuals aged $60-69$ years; $13.9 \mathrm{~s}$ and $1.6 \mathrm{~s}$ for individuals aged between 70 and 79 years; and $9.3 \mathrm{~s}$ and $0.6 \mathrm{~s}$ for individuals aged 80 years or older, respectively ${ }^{19}$.

The FRT was used also to determine the risk of falls. This test assesses a patient's stability by measuring the maximum distance an individual can reach forward while standing in a fixed position. The patient was instructed to stand close to, but not touching, a wall and position the arm that was closer to the wall at 90 degrees of shoulder flexion with a closed fist. The assessor records the starting position at the $3^{\text {rd }}$ metacarpal head on the yardstick and instruct the patient to "Reach as far as you can forward without taking a step" and then the location of the 3rd metacarpal was recorded. The difference between the start and end position was registered. The test was performed three times and the highest distance was considered. Elderly persons who could reach $15 \mathrm{~cm}$ or less had a 2-fold higher risk of falling than those who could reach between $15 \mathrm{~cm}$ and $25.4 \mathrm{~cm}$, and a 4 -fold higher risk of falling than those who could reach further than $25.4 \mathrm{~cm}^{20}$.

The FES-I aims to assess the fear of falling of the elderly individual ${ }^{11}$. The scale comprises questions that assess the concern about the possibility of falling during the performance of 16 activities. Each activity receives a score from one to four points, providing a total score ranging from 16 (absence of concern) to 64 (extreme concern). Thus, lower scores indicate more confidence and higher scores indicate lack of confidence and greater fear of falling. A score greater than or equal to 23 on this scale was associated with sporadic falls, and a score higher than 31 points was associated with recurrent falls. According to Carmagos et al. (2010) ${ }^{11}$, the total score is the element most closely associated with the outcome "fall in the previous year." Morgan et al. (2013) 22 found the FES-I has high test-retest reliability and convergent validity with other self-reporting and performance measures in individuals with dizziness and imbalance.

\section{Data analysis}

The collected data was electronically stored and analysed using the Statistics Package for the Social Sciences (SPSS) version 20.0. Data were submitted to descriptive analysis with measurement of central tendency and dispersion (mean and standard deviation). The Kolmogorov-Smirnov test demonstrated normal distribution for the variables. The dependent variable of the study (quality of life measured by the physical, functional and emotional aspects of the DHI - quantitative variable) was tested with the independent variables, which were then categorized through the Student's $t$-test and one-way ANOVA associated to Tukey's post-hoc test in order to search for associations. The level of significance was set at $5 \%$.

\section{RESULTS}

Among the 30 subjects, the mean age was 77.6 years with the age group 70-79 years being the most prevalent $(46.6 \%)$. The majority of the subjects $(53.3 \%)$ were female and $73.3 \%$ of the elderly persons had fallen in the previous year. A total of $54.5 \%$ of those who had suffered a fall were female. Five elderly (16.7\%) used walking aids.

Regarding the dizziness classification, the most frequent type found in this study was vertigo (60\%) (Figure 1). A total of $43.3 \%$ of the seniors said they displayed neurovegetative symptoms in association with dizziness, and $46.6 \%$ said they had unilateral or bilateral tinnitus. Regarding the duration of dizziness, $56.7 \%$ presented dizziness for minutes, $23.3 \%$ for seconds, $10 \%$ for hours and $10 \%$ for days.

The mean $\mathrm{DHI}$ score was $43.3 \pm 26.7$ points, which represents a low self-perception of quality of life related to dizziness. Associations were found between the physical, functional and emotional sub-scales of the $\mathrm{DHI}$ and the duration of dizziness, functional aspects of the DHI with age, physical aspects of DHI with falls in the previous years and physical, functional and emotional aspects with fear of falling (Figure 2). 


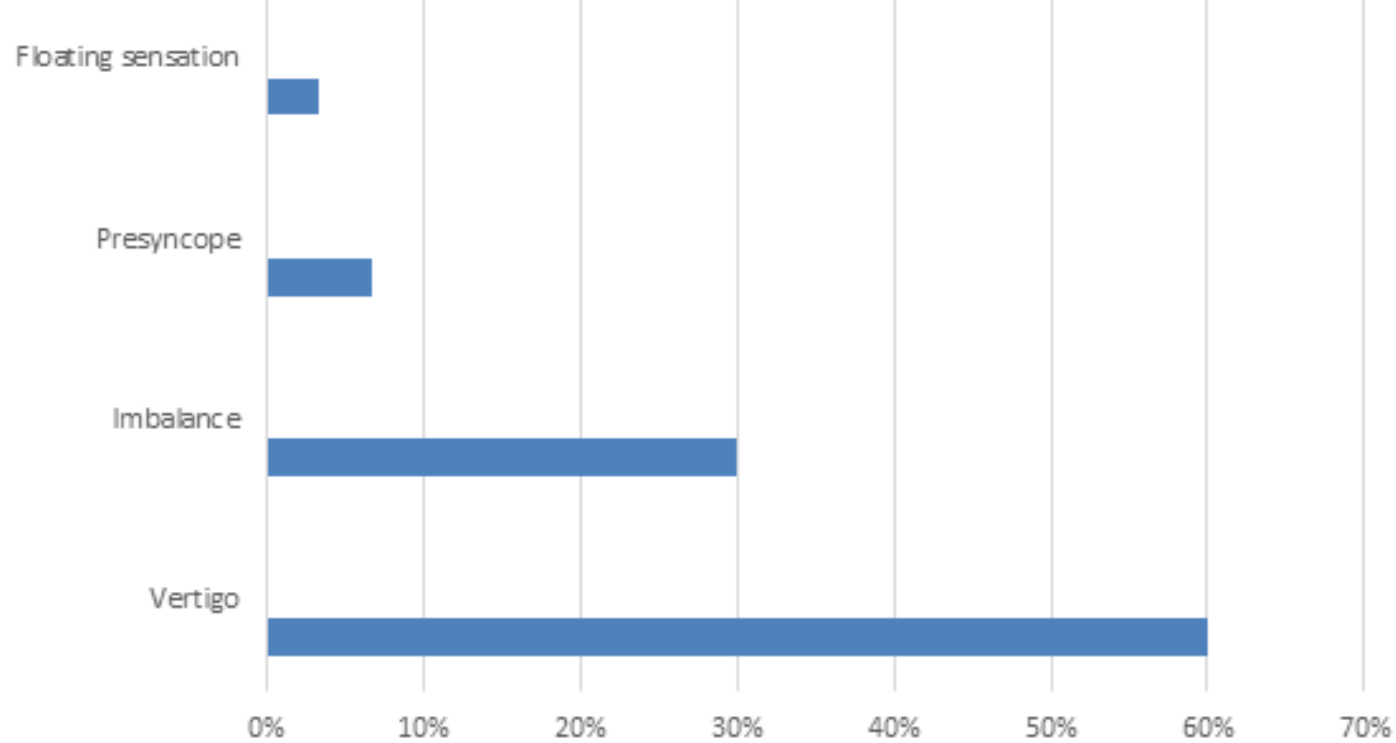

Figure 1. Type of dizziness of the institutionalized elderly. Natal, Brazil, 2017

\begin{tabular}{|c|c|c|c|c|c|c|c|}
\hline & \multirow{2}{*}{$n=30$} & \multicolumn{2}{|c|}{ DHI physical aspects } & \multicolumn{2}{|c|}{ DHI functional aspects } & \multicolumn{2}{|c|}{ DHI emotional aspects } \\
\hline & & Mean \pm SD & $p$ & Mean \pm SD & $p$ & Mean \pm SD & $p$ \\
\hline \multicolumn{8}{|l|}{ Sociodemographic data } \\
\hline Age $^{*}$ & & & \multirow{4}{*}{0.122} & & \multirow{4}{*}{0.031} & & \multirow{4}{*}{0.215} \\
\hline $60-69$ years & 4 & $8.5 \pm 6.2$ & & $7.5 \pm 3.4^{\mathrm{a}}$ & & $6.0 \pm 5.2$ & \\
\hline $70-79$ years & 14 & $10.4 \pm 6.1$ & & $15.3 \pm 11.0^{a . b}$ & & $13.7 \pm 9.8$ & \\
\hline 80 years or more & 12 & $15.2 \pm 7.4$ & & $23.7 \pm 11.7^{\mathrm{b}}$ & & $16.7 \pm 11.7$ & \\
\hline Sex** & & & \multirow{3}{*}{0.718} & & \multirow{3}{*}{0.424} & & \multirow{3}{*}{0.588} \\
\hline Males & 14 & $12.6 \pm 7.2$ & & $15.7 \pm 12.8$ & & $15.0 \pm 10.8$ & \\
\hline Females & 16 & $11.6 \pm 7.0$ & & $19.2 \pm 11.0$ & & $12.9 \pm 10.4$ & \\
\hline \multicolumn{8}{|c|}{ Characteristics of dizziness } \\
\hline Type of dizziness* & & & \multirow{5}{*}{0.598} & & \multirow{5}{*}{0.823} & & \multirow{5}{*}{0.915} \\
\hline Vertigo & 18 & $13.2 \pm 7.1$ & & $17.4 \pm 10.7$ & & $14.3 \pm 10.0$ & \\
\hline Imbalance & 9 & $11.3 \pm 7.3$ & & $16.2 \pm 14.5$ & & $12.0 \pm 12.6$ & \\
\hline Presyncope & 2 & $7.0 \pm 4.2$ & & $20.0 \pm 17.0$ & & $16.0 \pm 11.3$ & \\
\hline Floating sensation & 1 & $8.0 \pm 0.0$ & & $28.0 \pm 0.0$ & & $18.0 \pm 0.0$ & \\
\hline \multicolumn{8}{|l|}{ Duration of dizziness* } \\
\hline Seconds & 7 & $8.9 \pm 7.1^{\mathrm{a}}$ & \multirow{4}{*}{0.002} & $11.7 \pm 8.2^{\mathrm{a}}$ & \multirow{4}{*}{0.041} & $4.6 \pm 6.6^{a}$ & \multirow{4}{*}{0.004} \\
\hline Minutes & 17 & $11.2 \pm 5.2^{\mathrm{a} . \mathrm{c}}$ & & $16.3 \pm 12.3^{\mathrm{a}}$ & & $15.1 \pm 9.5^{b}$ & \\
\hline Hours & 3 & $11.3 \pm 2.3^{a . c . d}$ & & $22.7 \pm 8.3^{a}$ & & $12.7 \pm 10.3^{\mathrm{a}}$ & \\
\hline Days & 3 & $25.3 \pm 4.6^{\mathrm{b}}$ & & $33.3 \pm 2.3^{b}$ & & $28.0 \pm 0.0^{\mathrm{b}}$ & \\
\hline \multicolumn{8}{|c|}{ Seurovegetative symptoms ** } \\
\hline Yes & 13 & $12.8 \pm 8.0$ & \multirow{2}{*}{0.638} & $18.5 \pm 12.5$ & \multirow{2}{*}{0.734} & $16.8 \pm 8.6$ & \multirow{2}{*}{0.180} \\
\hline No & 17 & $11.5 \pm 6.3$ & & $16.9 \pm 11.6$ & & $11.6 \pm 11.4$ & \\
\hline Tinnitus** & & & & & & & \\
\hline Yes & 14 & $14.6 \pm 7.6$ & \multirow{2}{*}{0.065} & $20.3 \pm 14.1$ & \multirow{2}{*}{0.267} & $16.6 \pm 11.2$ & \multirow{2}{*}{0.190} \\
\hline No & 16 & $9.9 \pm 5.7$ & & $15.2 \pm 9.3$ & & $11.5 \pm 9.5$ & \\
\hline \multicolumn{8}{|l|}{ Use of a walking aid ${ }^{\star \star}$} \\
\hline Yes & 4 & $10.5 \pm 3.8$ & \multirow{2}{*}{0.683} & $28.0 \pm 8.6$ & \multirow{2}{*}{0.057} & $18.5 \pm 10.5$ & 0250 \\
\hline No & 26 & $12.3 \pm 7.4$ & & $16.0 \pm 11.5$ & & $13.1 \pm 10.5$ & 0.350 \\
\hline Previous falls** & & & & & & & \\
\hline Yes & 22 & $13.6 \pm 6.9$ & 0030 & $19.0 \pm 11.7$ & ח020 0 & $15.10 \pm 10.7$ & 0200 \\
\hline No & 8 & $7.7 \pm 5.5$ & 0.039 & $13.7 \pm 12.1$ & 0.290 & $10.50 \pm 9.5$ & 0.296 \\
\hline
\end{tabular}




\begin{tabular}{|c|c|c|c|c|c|c|c|}
\hline & \multirow{2}{*}{$n=30$} & \multicolumn{2}{|c|}{ DHI physical aspects } & \multicolumn{2}{|c|}{ DHI functional aspects } & \multicolumn{2}{|c|}{ DHI emotional aspects } \\
\hline & & Mean \pm SD & $p$ & Mean \pm SD & $p$ & Mean \pm SD & $p$ \\
\hline \multicolumn{8}{|c|}{ Functional capacity } \\
\hline \multicolumn{8}{|l|}{$\mathrm{BBS}^{\star \star}$} \\
\hline$<=45$ & 21 & $12.7 \pm 7.3$ & 0.482 & $19.7 \pm 11.8$ & 0.137 & $15.5 \pm 10.7$ & 0.190 \\
\hline$>45$ & 9 & $10.7 \pm 6.4$ & & $12.7 \pm 11.0$ & & $10.0 \pm 9.2$ & \\
\hline \multicolumn{8}{|l|}{ FES $-I^{*}$} \\
\hline$<23$ & 5 & $6.8 \pm 3.9^{a}$ & 0004 & $6.8 \pm 5.2^{\mathrm{a}}$ & & $6.8 \pm 4.8^{a}$ & \\
\hline 23 а 31 & 9 & $8.4 \pm 4.8^{\mathrm{a} . \mathrm{c}}$ & 0.004 & $10.4 \pm 6.3^{3 . c}$ & $<0.001$ & $9.1 \pm 7.4^{a . c}$ & 0.016 \\
\hline$>31$ & 16 & $15.7 \pm 6.8^{b}$ & & $25.0 \pm 10.7^{b}$ & & $18.7 \pm 11.0^{\mathrm{b}}$ & \\
\hline \multicolumn{8}{|l|}{ FRT* } \\
\hline$<15 \mathrm{~cm}$ & 15 & $12.8 \pm 6.7$ & & $18.7 \pm 11.5$ & & $14.4 \pm 11.2$ & \\
\hline 15 a $24,5 \mathrm{~cm}$ & 12 & $10.8 \pm 8.2$ & 0.740 & $17.3 \pm 13.6$ & 0.784 & $14.8 \pm 10.7$ & 0.84 \\
\hline$>24,5 \mathrm{~cm}$ & 3 & $13.3 \pm 1.1$ & & $13.3 \pm 6.1$ & & $7.3 \pm 3.0$ & \\
\hline \multicolumn{8}{|l|}{ UST EO**, \# } \\
\hline Normal & 4 & $10.0 \pm 2.8$ & 0534 & $9.0 \pm 6.0$ & 0.120 & $11.5 \pm 5.7$ & 0.472 \\
\hline Alterado & 26 & $12.4 \pm 7.4$ & 0.504 & $18.9 \pm 12.0$ & 0.120 & $14.2 \pm 11.0$ & 0.472 \\
\hline \multicolumn{8}{|l|}{ UST EC**.\# } \\
\hline Normal & 4 & $14.0 \pm 7.1$ & 0561 & $14.0 \pm 15.1$ & 0.523 & $13.5 \pm 9.7$ & 0942 \\
\hline Abnormal & 26 & $11.8 \pm 7.0$ & 0.001 & $18.1 \pm 11.5$ & $0.0<0$ & $13.9 \pm 10.7$ & 0.546 \\
\hline
\end{tabular}

\# Cut-off point for UST per age: 60-69 years: EO: 16.6; EC:2.2; 70-79: E0: 13.9; EC: 1.6; 80-99: E0:9.3; EC: 0.6; *ANOVA; ** Student's t test.

a. b. c. d: equal letters do not show a statistical significant difference in post-hoc test.

SD: Standard deviation; BBS: Berg Balance Scale; FES-I: Falls Efficacy Scale - International; FRT: Functional Reach Test; UST EO: Unipedal Stance Test - eyes open; UST EC: Unipedal Stance Test - eyes closed.

Figure 2. Association between physical, functional and emotional aspects of Dizziness Handicap Inventory with socio-demographic data related to dizziness and functional capacity. Natal, Brazil, 2017 
Table 1 presents the means and standard deviations of the sample in the functional tests. It was observed that women had lower mean test scores and that elderly persons aged between 60 to 69 years had higher mean scores than those aged over 70 years.

Table 1. Descriptive analysis of Berg Balance Scale, Falls Efficacy Scale - International, Functional Reach Test and Unilateral Stance with open and closed eyes performance, in relation to sex and age group. Natal, Brazil, 2017

\begin{tabular}{|c|c|c|c|c|c|}
\hline & & $n$ & MIN & MAX & MEAN \pm SD \\
\hline \multirow[t]{8}{*}{ BBS } & & 30 & 9 & 55 & $39.0( \pm 9.8)$ \\
\hline & Sex & & & & \\
\hline & Females & 16 & 9 & 51 & $37.0( \pm 9.9)$ \\
\hline & Males & 14 & 23 & 55 & $41.3( \pm 9.6)$ \\
\hline & Age group & & & & \\
\hline & $60-69$ years & 4 & 39 & 55 & $47.5( \pm 6.5)$ \\
\hline & $70-79$ years & 14 & 29 & 48 & $38.1( \pm 6.6)$ \\
\hline & 80 and older & 12 & 9 & 51 & $37.2( \pm 12.7)$ \\
\hline \multirow[t]{8}{*}{ FES-I } & & 30 & 16 & 56 & $34.0( \pm 10.6)$ \\
\hline & Sex & & & & \\
\hline & Females & 16 & 21 & 53 & $36.0( \pm 8.9)$ \\
\hline & Males & 14 & 16 & 56 & $31.6( \pm 12.3)$ \\
\hline & Age group & & & & \\
\hline & $60-69$ years & 4 & 16 & 35 & $24.7( \pm 9.7)$ \\
\hline & $70-79$ years & 14 & 16 & 51 & $33.1( \pm 8.8)$ \\
\hline & 80 and older & 12 & 20 & 56 & $38.0( \pm 11.5)$ \\
\hline \multirow[t]{8}{*}{ FRT } & & 30 & 3.7 & 31.3 & $16.8( \pm 6.8)$ \\
\hline & Sex & & & & \\
\hline & Females & 16 & 9.3 & 22.2 & $15.8( \pm 5.9)$ \\
\hline & Males & 14 & 3.7 & 31.3 & $16.5( \pm 7.6)$ \\
\hline & Age group & & & & \\
\hline & $60-69$ years & 4 & 11.67 & 31.3 & $23.3( \pm 8.4)$ \\
\hline & $70-79$ years & 14 & 6.3 & 21.3 & $14.5( \pm 4.6)$ \\
\hline & 80 and older & 12 & 3.7 & 22.2 & $13.8( \pm 7.8)$ \\
\hline \multirow[t]{7}{*}{ UST with eyes open } & & 30 & 0 & 30 & $1.8( \pm 3.7)$ \\
\hline & Sex & & & & \\
\hline & Females & 16 & 0 & 22 & $1.7( \pm 5.5)$ \\
\hline & $\begin{array}{c}\text { Males } \\
\text { Age }\end{array}$ & 14 & 0 & 30 & $7.1( \pm 10.2)$ \\
\hline & $60-69$ years & 4 & 0 & 26.9 & $9.3( \pm 12.1)$ \\
\hline & 70-79 years & 14 & 0 & 30 & $4.1( \pm 9.5)$ \\
\hline & 80 and older & 12 & 0 & 16.0 & $2.3( \pm 4.8)$ \\
\hline \multirow[t]{8}{*}{ UST with eyes closed } & & 30 & 0 & 6.9 & $0.8( \pm 1.8)$ \\
\hline & Sex & & & & \\
\hline & Females & 16 & 0 & 1.2 & $1.7( \pm 0.3)$ \\
\hline & Males & 14 & 0 & 6.9 & $0.1( \pm 2.3)$ \\
\hline & Age group & & & & \\
\hline & $60-69$ years & 4 & 0 & 2.9 & $1.4( \pm 1.7)$ \\
\hline & 70-79 years & 14 & 0 & 6.9 & $0.0( \pm 2.1)$ \\
\hline & 80 and older & 12 & 0 & 5.0 & $0.0( \pm 1.4)$ \\
\hline
\end{tabular}

Legend: SD: Standard deviation; BBS: Berg Balance Scale; FES-I: Falls Efficacy Scale - International; UST: Unilpedal Stance Test with eyes open and closed (seconds); FRT: Functional Reach Test (cm); MIN: Minimum; MAX: Maximum; n: number of individuals. 


\section{DISCUSSION}

There is a lack of studies aiming to evaluate quality of life and functional capacity in institutionalized elderly persons with dizziness complaints. Dizziness is a symptom closely related to falls in the elderly, especially among institutionalized elderly ${ }^{23}$. In the present study, $73.3 \%$ of the elderly persons reported having experienced one or more falls in the last year. The number of falls experienced by the elderly is important due to the possibility of complications and the high rate of morbidity and mortality associated with falls, with serious implications for public health. In this study, it was observed that the majority of elderly individuals who reported falls were female. Literature shows that women have a 2.5 times higher risk of falling than men $^{24}$. A meta-analysis by Ueno et al. (2006) ${ }^{25}$ identified that being female and aged over 70 years are among the factors most related to falls.

When assessing the quality of life in an individual with dizziness, regardless of the instrument being used, the invariable conclusion is that this symptom leads to great negative interference in the individual's life. In the elderly, this impact is even greater ${ }^{26}$. Age is an important factor, as the loss of independence and the decrease in function level increase as people age. Studies associate functionality scales to physical mobility, strength and balance tests, and affirm that elderly with low self-confidence to perform ADLs are in potential risk of social isolation and a sedentary lifestyle over time. This reflects in a negative evaluation of their quality of life ${ }^{27}$. This study found that age is associated to a decrease in functional aspects of the quality of life, corroborating with literature.

It was observed that dizziness time onset influences physical, functional and emotional aspects of the $\mathrm{DHI}$, and that seconds, minutes, hours and days interfere in it in different ways. Studies that present differences between the duration of dizziness and $\mathrm{DHI}$ were not found. However, studies show that the diseases that lead to transient dizziness present higher commitment of the physical aspects evaluated by the DHI. Nevertheless, emotional aspects occur as a consequence of the long lasting physical limitations and functional incapacily due to dizziness ${ }^{28}$. Psychological fators are largely known as triggers for dizziness and therefore may be associated to a low score in quality of life scales ${ }^{29}$.

In the analysis of the other data related to dizziness, the literature lists great interference of tinnitus and other symptoms related to worsening of the patient's quality of life ${ }^{30,31}$. However, an association between the otoneurological symptoms and the aspects assessed by the DHI were not found in this study. The low number of participants in this study may have influenced these results.

Elderly persons with poor physical performance as reported by the $\mathrm{DHI}$ had also fallen in the previous year. Prevalence of falls has been associated with advanced age, a sedentary lifestyle, poor perception of health and a greater number of medications used continuously ${ }^{32}$. Fisher et al. (2005) ${ }^{33}$ and Rebellato et al. (2007) ${ }^{23}$ added that institutionalized elderly are more sedentary. Other studies have also found a correlation between physical fitness and falls, with different ways of evaluating muscle strength such as maximum isometric strength of the quadriceps $\mathrm{s}^{34}$ and the 30 s chair-stand test ${ }^{35}$.

The fear of falling measured by the FES-I revealed an association with the three aspects of the quality of life assessment (physical, functional and emotional). This means that insecurity to walk prevents an older adult from performing many of their ADLs, limits their physical capacity and interferes in their emotional capacity as it restricts their social support network. Moreover, it is known that patients with vestibular dysfunction have decreased confidence in their balance and consequently are at an increased risk of falling ${ }^{36}$.

It is expected that elderly with dizziness present worse performance on physical functioning tests. In the present study, older people (80 or more) obtained worse scores on all functional capacity tests. According to the BBS, only elderly ranging between 60 and 69 years old did not present a high risk of falling as established by a cut-off point $\leq 45^{16}$, and the total score was lower than ones from previous studies ${ }^{17,37}$. The total FRT means showed scores $(16.8 \mathrm{~cm})$ close to the high risk of falling range $(\leq 15 \mathrm{~cm})$. In groups of ages, elderly aged 70 or more years present twice the risk of falling than those aged between 60 and 69 years old ${ }^{20}$. An expressive decreasing functionality and a loss in the capacity to adapt is observed with the aging process, which is associated to large changes that affect mobility, autonomy and the health of the elderly population ${ }^{38}$.

According to the results, elderly participants of all ages presented high risk of falls. Institutionalized elderly present higher rates of fragility, which is predictive to the loss of functional capacity, than communitydwelling elderly. In a retrospective study ${ }^{39}$, it was determined that this is also a marker for recurrent falls. In this sense, impairment of functional capacity resulting 
from this fragility seems to play an important role in the multicausal interaction of falls in institutionalized elderly ${ }^{27}$. The literature indicates that institutionalized elderly individuals generally present equivalent scores for a risk of falling in functional capacity tests ${ }^{23,40}$, confirming that a decrease in strength, balance and mobility resulting from the institutionalization process are important factors for their low performance on the testing and reflect an increased risk for falls. In this study, it was found that the older the individual is, the lower the UST time, which corroborates the literature ${ }^{19}$.

Despite the performance of women on the tests was found to be lower than that of men, it cannot be inferred that gender is related to lower quality of life or loss of function. However, descriptive statistics identified a trend towards lower performance among women and in older age groups, possibly being the result of the limitations of the small sample size.

The main limitation of the study was the impossibility to apply the results more comprehensively due to small sample size, since many elderly persons who live in HA present a low cognitive level or did not meet the inclusion criteria of the study. Moreover, it was not possible to compare functional performance and quality of life between institutionalized elderly persons with or without dizziness due to the number of HA included in this study.

However, the implications of these findings for the rehabilitation field are based on the fact that there are few studies that evaluate these parameters in institutionalized elderly persons. Therefore, the increasing knowledge of the performance of individuals on functional tests may allow the environment in which they live to be adapted to improve their daily practices, and to develop specific treatment plans for their disabilities.

\section{CONCLUSION}

In the present study, institutionalized elderly persons with dizziness complaints had a low self-perception of quality of life, and the duration of dizziness, age, falls and fear of falling negatively influenced their quality of life. Furthermore, older institutionalized elderly people presented worse performance on functional capacity tests, which may lead to a higher risk of falls.

\section{REFERENCES}

1. Luppa M, Luck T, Weyerer S, Konig HH, Brahler E, Riedel-Heller SG. Prediction of institutionalization in the elderly: a systematic review. Age Ageing. 2010;39(1):31-8.

2. Dechamps $A$, Diolez $P$, Thiaudiere $E$, Tulon $A$, Onifade $\mathrm{C}$, Vuong $\mathrm{T}$ et al. Effects of exercise programs to prevent decline in health-related quality of life in highly deconditioned institutionalized elderly persons: a randomized controlled trial. Arch Intern Med. 2010;170(2):162-9.

3. De Luca d'Alessandro E, Bonacci S, Giraldi G. Aging populations: the health and quality of life of the elderly. Clin Ter. 2011;162(1):e13-8.

4. Del Duca GF, Silva SG, Thume E, Santos IS, Hallal $\mathrm{PC}$. Predictive factors for institutionalization of the elderly: a case-control study. Rev Saude Publica. 2012;46(1):147-53.

5. Ferreira LMBM, Ribeiro KMOBF, Freitas RVM, Roig JJ, Lima KC. Risk factors of dizziness among institutionalized elderly persons: a case control study. J Gerontol Geriatr Res. 2016;6(1):1-5.

6. Ferreira LMBM, RIbeiro KMOBF, Lima KC. Prevalence of dizziness and associated factors in institutionalized elderly persons. J Surg Cl Res. 2015;6(2):45-56.

7. Borges LL, Garcia PA, Ribeiro SRV. Características clínico-demográficas, equilíbrio funcional de idosos institucionalizados e comunitários. Fisioter Mov. 2009;22(1):53-60.

8. Ganança MM, Caovilla HH, Ganança FF, Doná F, Branco-Barreiro F, Paulino CA et al. Como diagnosticar e tratar vertigem. Rev Bras Med. 2008;65(12):6-14.

9. Dhargave $P$, Sendhilkumar R. Prevalence of risk factors for falls among elderly people living in long-term care homes. J Clin Gerontol Geriatr. 2016;7(3):99-103.

10. Organização Mundial da Saúde, Organização Panamericana de Saúde, Centro Colaborador da OMS para Classificação de Doenças em Português. Classificação Internacional de incapacidade, funcionalidade e saúde (CIF). São Paulo: EDUSP; 2003.

11. Camargos FF, Dias RC, Dias JM, Freire MT. Cross-cultural adaptation and evaluation of the psychometric properties of the Falls Efficacy Scale-International among elderly brazilians (FES-IBRAZIL). Rev Bras Fisioter. 2010;14(3):237-43. 
12. Malta M, Cardoso L, Bastos F, Magnanini M, Silva C. STROBE initiative: guidelines on reporting observational studies. Rev Saude Publica. 2010;44(3):559-65.

13. Castro AS, Gazzola JM, Natour J, Gananca FF. Brazilian version of the dizziness handicap inventory. Pro Fono R Atual. Cientif. 2007;19(1):97-104.

14. Jacobson GP, Newman CW. The development of the Dizziness Handicap Inventory. Arch Otolaryngol Head Neck Surg. 1990;116(4):424-7.

15. Drachman DA, Hart CW. An approach to the dizzy patient. Neurology. 1972;22(4):323-34.

16. Berg KO, Wood-Dauphinee SL, Williams JI, Maki $B$. Measuring balance in the elderly: validation of an instrument. Can J Public Heal. 1992;83(Suppl 2):S7-11.

17. Whitney S, Wrisley D, Furman J. Concurrent validity of the Berg Balance Scale and the Dynamic Gait Index in people with vestibular dysfunction. Physiother Res Int. 2003;8(4):178-86.

18. Hurvitz EA, Richardson JK, Werner RA, Ruhl AM, Dixon MR. Unipedal stance testing as an indicator of fall risk among older outpatients. Arch Phys Med Rehabil. 2000;81(5):587-91.

19. Springer BA, Marin R, Cyhan T, Roberts H, Gill NW. Normative values for the unipedal stance test with eyes open and closed. J Geriatr Phys Ther. 2007;30(1):8-15.

20. Duncan PW, Weiner DK, Chandler J, Studenski S. Functional reach: a new clinical measure of balance. J Gerontol. 1990;45(6):M192-7.

21. Miyamoto ST, Lombardi Junior I, Berg KO, Ramos LR, Natour J. Brazilian version of the Berg balance scale. Braz J Med Biol Res. 2004;37(9):1411-21.

22. Morgan MT, Friscia LA, Whitney SL, Furman JM, Sparto PJ. Reliability and validity of the Falls Efficacy Scale-International (FES-I) in individuals with dizziness and imbalance. Otol Neurotol. 2013;34(6):1104-8.

23. Rebelato JR, de Castro AP, Chan A. Falls in institutionalized elderly people: general characteristics, determinant factors and relationship with handgrip strength. Acta Ortop Bras. 2007;15(3):151-4.

24. Perracini MR, Ramos LR. Fall-related factors in a cohort of elderly community residents. Rev Saude Publica. 2002;36(6):709-16.
25. Ueno M, Kawai S, Mino T, Kamoshita H. Systematic review of fall-related factors among the housedwelling elderly in Japan. Nihon Ronen Igakkai Zasshi. 2006;43(1):92-101.

26. Ciorba A, Bianchini C, Scanelli G, Pala M, Zurlo A, Aimoni C. The impact of dizziness on qualityof-life in the elderly. Eur Arch Otorhinolaryngol. 2017;274(3):1245-50.

27. Lopes KT, Costa DF, Santos LF, Castro DP, Bastone AC. Prevalence of fear of falling among a population of older adults and its correlation with mobility, dynamic balance, risk and history of falls. Braz J Phys Ther. 2009;13(3):223-9.

28. Handa PR, Kuhn AM, Cunha F, Schaffleln R, Gananca FF. Quality of life in patients with benign paroxysmal positional vertigo and/ or Meniere's disease. Braz J Otorhinolaryngol. 2005;71(6):776-82.

29. Weidt S, Bruehl AB, Straumann D, Hegemann SC, Krautstrunk G, Rufer M. Health-related quality of life and emotional distress in patients with dizziness: a cross-sectional approach to disentangle their relationship. BMC Health Serv Res. 2014;14(1):317.

30. Dag E, Bayar Muluk N, Karabicak H, Kursat Arikan O, Turkel Y. Cognitive Evaluation and Quality of Life Assessment in Patients with Subjective Tinnitus. Acta Neurol Taiwan. 2016;25(1):1-9.

31. Riedl D, Rumpold G, Schmidt A, Zorowka PG, Bliem HR, Moschen R. The influence of tinnitus acceptance on the quality of life and psychological distress in patients with chronic tinnitus. Noise Health. 2015;17(78):374-81.

32. Siqueira F V, Facchini LA, Piccini RX, Tomasi E, Thume E, Silveira DS et al. Prevalência de quedas em idosos e fatores associados. Rev Saude Publica. 2007;41(5):749-56.

33. Fisher AA, Davis MW, McLean AJ, Le Couteur DG. Epidemiology of falls in elderly semi-independent residents in residential care. Australas $\mathrm{J}$ Ageing. 2005;24(2):98-102.

34. Al-Abdulwahab SS. The effects of aging on muscle strength and functional ability of healthy Saudi Arabian males. Ann Saudi Med. 1999;19(3):211-5.

35. Ishizuka MA, Mutarelli EG, Yamaguchi AM, Jacob Filho W. Falls by elders with moderate levels of movement functionality. Clinics. 2005;60(1):41-6. 
36. Legters K, Whitney SL, Porter R, Buczek F. The relationship between the Activities-specific Balance Confidence Scale and the Dynamic Gait Index in peripheral vestibular dysfunction. Physiother Res Int. 2005;10(1):10-22.

37. Caixeta GC, Dona F, Gazzola JM. Cognitive processing and body balance in elderly subjects with vestibular dysfunction. Braz J Otorhinolaryngol. 2012;78(2):87-95.

38. Carvalho J, Soares JMC. Envelhecimento e força muscular: breve revisão. Rev Port Cien Desp. 2004;4(3):79-93.

39. de Vries OJ, Peeters GM, Lips P, Deeg DJ. Does frailty predict increased risk of falls and fractures? A prospective population-based study. Osteoporos Int. 2013;24(9):2397-403.

40. Alvarez Barbosa F, Del Pozo-Cruz B, Del Pozo-Cruz J, Alfonso-Rosa RM, Sanudo Corrales B, Rogers ME. Factors associated with the risk of falls of nursing home residents aged 80 or older. Rehabil Nurs. 2016;41(1):16-25. 